\title{
HACIA UNA HISTORIA DEL PENSAMIENTO ECONOMICO EN ESPAÑA. UNAS SUGERENCIAS METODOLOGICAS ${ }^{1}$
}

\author{
PEDRO SCHWARTZ GIRON \\ Universidad Complutense de Madrid
}

Con las presentes notas no pretendo sino lanzar la discusión entre los asistentes a estas III Jornadas sobre el enfoque conveniente para ir realizando entre todos la historia del pensamiento económico en España. Es ésta una tarea de mucha complejidad, a la que ya venimos contribuyendo los economistas e historiadores desde hace al menos dos siglos según nuestro leal saber y entender, por lo que no pretendo haber descubierto la piedra filosofal.

Voy a exponer con toda claridad mis puntos de vista, sin pretender imponerlos a nadie. Unicamente servirá esta exposición para aviso de caminantes, en el sentido de que en ella aparecen las pautas según las que evalúo los trabajos de mis compañeros en este campo, tanto cuando digo mi crítica en público como cuando callo prudentemente.

\section{Realismo e individualismo metodológicos}

Comienzo por decir que el mundo existe ahí fuera, aunque no sabemos a ciencia cierta cómo es. En este mundo rigen unas leves naturales sobre las que continuamente lanzamos hipótesis. Si estas hipótesis no se acercaran algo a la realidad no habría sobrevivido la raza humana. De aquí que la mejor manera de ir refinando el contenido de nuestros conocimientos consiste en contrastar nuestra hipótesis con la realidad. Tal contrastación no es sencilla, especialmente en las ciencias sociales, pero es la única manera de adivinar si nos equivocamos antes de darnos de bruces con la realidad y malherirnos seriamente. En apoyo de estas mis tesis metodológicas, he escrito un artículo sobre Darwin y Popper, titulado «Karl Popper y la teoría de la evolución» ${ }^{2}$.

El mundo social es un mundo tan opaco y resistente como el natural. Es cierto que sabemos que ese mundo social lo hemos creado los hombres

' Primera versión presentada en las III Jornadas de Historia del Pensamiento Econó. mico, Barcelona, 11-12 de diciembre de 1987.

2 Schwartz (1987), pp. 443.456. 
con nuestras acciones y reacciones frente a los impulsos de nuestros congéneres y dentro de las constricciones que nos imponen las leyes naturales. Las leyes sociales no imponen conductas, como tampoco lo hacen las naturales: prohíben conductas imposibles. Así, no es posible construir una máquina de movimiento continuo; tampoco es posible emitir a la continua papel moneda y evitar que suban los precios expresados en esa moneda; $\mathbf{u}$ of recer servicios públicos de salud gratuitos y que no aparezcan colas. Detrás de estas imposibilidades se encuentran: la segunda ley de la termodinámica; la ley «de la cantidad de dinero de los precios»; y la «ley de la demanda» (o de que la demanda de un bien escaso con precio cero es infinital.

La manera de construir hipótesis para entender el mundo social es partir del supuesto de que todos los fenómenos sociales son reducibles a las acciones y reacciones de los individuos. Todo fenómeno supraindividual, cual sería una tradición, una institución, un idioma, tiene que ser modelizable en términos de acciones individuales y de la información que los individuos tienen sobre las condiciones iniciales de las que parten.

\section{Mercado y Metamercado}

Una de las cosas que hemos aprendido los científicos sobre la sociedad es que el mercado funciona perfectamente. Partiendo de la hipótesis de acción racional interesada de los individuos, y de los objetivos inmanentes de esos individuos (pues no somos nadie para juzgar los fines perseguidos por los demás, sólo podemos decir que nos negamos a contratar con ellos), los resultados que arroja el funcionamiento social son siempre óptimos.

Esta chocante afirmación se entiende en cuanto digo que el locus de las disfunciones sociales es el «metamercado». Si suponemos que la sociedad es un contrato virtual y permanente por el que continuamente evaluamos los individuos los costes de mantenernos en ella, nuestra atención como economistas políticos debe centrarse en los contratos constitucionales y no en sus consecuencias mercantiles. En este sentido nos hemos afiliado los economistas en la escuela institucionalista (de Chicago). La atención de los economistas políticos, tras entender de la mejor manera posible el funcionamiento del mercado, se vuelve hacia las instituciones, pactos constitucionales, lógica de las decisiones políticas, es decir, hacia el «Public Choice» o «Teoría de la decisión pública». Mis argumentos en apoyo de esta postura mía aparecen en el trabajo «Market and Meta-market. A Review of the Contributions of the Economic Theory of Property Rights» ${ }^{3}$. El historiador, pues, deberá prestar atención a

\footnotetext{
${ }^{3}$ Suetozar (1987), pp. 11-32.
} 
cómo se ha ido construyendo la teoría del mercado, así como la teoría de las modificaciones que las instituciones del metamercado aportan al funcionamiento de aquél.

\section{La historia del pensamiento economico como progreso}

La historia del pensamiento económico que me interesa, pues, es la historia del progreso de nuestros conocimientos sobre el mecanismo del mercado y sobre las instituciones económicas con las que paliamos los costes de trabajar en este mundo, así como la historia de la influencia de nuestros conocimientos sobre el progreso (o regreso) de nuestras instituciones.

Referido todo esto a España, los historiadores del pensamiento económico buscamos descubrimientos y formulaciones acertadas en el campo del conocimiento económico realizadas en el ámbito de los idiomas españoles, así como influencias de las ideas económicas en las instituciones sociales del mundo hispano.

En mi humilde (pero humilde de verdad) opinión, hay que saber mucha teoría económica del mercado y de las instituciones económicas para explicar adecuadamente Historia del Pensamiento Económico; y no hay más que una teoría económica, aunque no sabemos a ciencia cierta y en todos sus detalles cuál es. Lo que sí sabemos es que mundo no hay más que uno, aunque ignoramos mayormente cómo funciona.

Como especialistas en el tema debemos contar como mejor sepamos la historia apasionante de la secuencia de los descubrimientos, las instituciones olvidadas y re-encontradas, los problemas irresolutos desde nuestra experiencia de historiadores.

Sociología de la ciencia: sus categorias

El tema propio de los historiadores de la ciencia económica es el del descubrimiento y la difusión de las visiones parciales de la realidad económica expresada en sus leyes, así como de las instituciones económicas resumidas en modelos.

Para ello debemos aventurarnos en el campo pantanoso de la sociología de la ciencia. ¿Cómo funciona el orden social de la ciencia que tanto influye en el descubrimiento, la difusión y el olvido parcial de tales visiones? Aquí aparecen cuestiones como la del rechazo y aceptación de las doctrinas, los programas de investigación y sus frutos, la difusión y el olvido de las ideas una vez descubiertas. 
Ayuda preciosa para estas investigaciones son las categorías propuestas por George Stigler para entender el funcionamiento de las escuelas. Una escuela nace alrededor del pensamiento original de uno o dos fundadores y su programa de investigación. Cuando éste o éstos mueren, los discípulos ya no pueden suministrar análisis original, y se contentan con promulgar reglas de política económica. El pensamiento de la escuela se difunde en ideología a través de la opinión pública. Tal esquema podría valer para tipificar algunos períodos del pensamiento económico español, por ejemplo el de los doctores escolásticos de los siglos XVI y XVII, o el de los escritores de la Ilustración conectados con la escuela histórica escocesa.

También es interesante la sugerencia de Stigler de que sólo en tiempos recientes han empezado los economistas a leerse y criticarse los unos a los otros y especialmente a buscar y ejercer la crítica de los mejores. Sin esa crítica no es posible el progreso científico. Por eso, dice Stigler, decayó el pensamiento económico durante la época mercantilista, respecto de la del Siglo de Oro. Esta intuición podría aplicarse también a épocas más recientes, por ejemplo en el siglo $\mathrm{xx}^{4}$.

En tercer lugar, es útil la distinción en «teorías», "doctrinas» y «opiniones» referidas a las teorías científicas, las doctrinas de escuelas, y las opiniones del vulgo, según el nivel de refinamiento alcanzado por las ideas que ha sido tradicional en las explicaciones universitarias de la escuela de Madrid. En cuarto lugar, debe ser objeto de investigación histórica la influencia del poder en el pensamiento, la interacción entre política económica y doctrina económica, y el efecto de los economistas sobre la realidad histórica (y viceversa). Si a estas categorías añadimos las distinciones nacionales, que tienen interés por el aislamiento de los tratadistas en sus idiomas, y por las refracciones de las ideas económicas en la realidad política de cada Estado o nacionalidad, podremos haber definido un marco bastante completo para continuar la obra de antiguos y presentes historiadores del pensamiento económico en España.

\section{Las categorias de la Historia del Pensamiento económico}

En resumen: parto de la idea de que no hay más que un mundo (desconocido), cuyo funcionamiento intentamos interpretar con nuestras ideas.

En el campo económico-sociológico, esta interpretación es realizada con tres instrumentos: 1) las leyes económicas del mercado, que se supone perfecto; 2) las instituciones del metamercado, que funcionan a saltos y con

\footnotetext{
4 Stigler (1983).
} 
grumos y que representamos en modelos basados también en las leyes de la economía; 3) las predicciones de comportamientos individuales agrupados, sobre la base de las leyes del mercado y de nuestros modelos resumidos de diversos marcos institucionales.

Los economistas del pasado han ido descubriendo a retazos partes de esta estructura interpretativa, las han ido interpretando encontradamente, las han olvidado o han seguido caminos erróneos.

La historia del pensamiento económico intenta trazar estos meandros, desde la (humilde) convicción de que en algunas cosas sabemos más que en el pasado. $Y$ para dar cuenta de los meandros usa categorías como: escuelas, sus fundadores y discípulos; teorías, doctrinas y opiniones; interacción entre doctrinas y política económica; diferencias nacionales. Todo ello supone un trabajo siempre inconcluso, quizá escrito desde puntos de vista parciales o interesados, pero muy útil para calmar la soberbia de los sabelotodos y moderar el escepticismo de los hastiados.

\section{BIBLIOGRAFIA}

SChWArtz, P. (1987): «Karl Popper y la teoría de la evolución», en Historia y pensamiento: bomenuic a Luis Diez del Corral (edición a cargo de $M$. Carmen Iglesias), Madrid, Universidad' Complutense, Editorial Eudema.

Stigler, G. J. (1983): «Nobel Lecture: The Process and Progress of Economics», en Journal of Political Economy, vol. 91, núm. 4, agosto.

Suetozar, Pejovich (ed.) (1987): Socialism: Institutional, Philosophical and Economic Issues, Boston, Kluwer Academic Publishers. 